総 説

\title{
内視鏡下血腫除去術の基本と応用
}

\author{
山本 拓史, 川村 海渡, 杉山 夏来, 鈴木 一幹 \\ 上野 英明, 渡邊 瑞也, 中尾 保秋
}

\section{Basic and Advanced Techniques for Endoscopic Hematoma Evacuation}

\author{
Takuji Yamamoto, M.D., Kaito Kawamura, M.D., Natsuki SugrYama, M.D., \\ Kazumoto Suzuki, M.D., Hideaki Ueno, M.D., Mitsuya Watanabe, M.D., and \\ Yasuaki NAKAO, M.D. \\ Department of Neurosurgery, Juntendo University Shizuoka Hospital, Izunokuni, Shizuoka, Japan
}

\begin{abstract}
Summary: Endoscopic hematoma evacuation is a key minimally invasive procedure learned by young neurosurgeons. It can help them to improve their surgical technique and understand the differences between techniques, including microscopic surgery. The surgical indication for endoscopic hematoma evacuation should be performed in compliance with the guidelines for stroke management.

The hematoma clots can be removed using a rigid endoscope and a suction tube in a transparent sheath. The surgical procedure is performed in four steps. First, the position of the burr hole should be determined. Second, a transparent sheath should be inserted into the hematoma cavity. This has to be done very carefully because a wrong trajectory may cause severe morbidity. The sheath tip should be guided to the boundary between the brain parenchyma and the hematoma. Third, hematoma aspiration should commence under an endoscopic view. Finally, a suction tube should be used as a probe adapted to the monopolar coagulator system for hemostasis. Continuous irrigation using artificial cerebrospinal fluid can also be useful for confirming the bleeding point.

Endoscopic hematoma evacuation may be advantageous than microscopic surgery for cerebellar hemorrhage and intraventricular hematoma (IVH). In patients with IVH, the hematoma can be removed from the bilateral lateral ventricle and third ventricle via a one-side anterior puncture. In patients with spontaneous cerebellar hemorrhage, it is possible to remove an intraparenchymal hematoma and a hematoma in the fourth ventricle through a single burr hole. Furthermore, the operation time and the hematoma removal ratio are significantly improved.
\end{abstract}

\section{はじめに}

内視鏡下血腫除去術は, 脳内出血の外科的治療において 開頭血腫除去術，定位脳内血腫吸引術と並び脳神経外科医

\author{
Key words: \\ $\cdot$ endoscope \\ - surgical technique \\ - intracerebral hemorrhage \\ $(\mathrm{ICH})$ \\ - intraventricular \\ hemorrhage (IVH)
}

Surg Cereb Stroke

(Jpn) 48: 190-195, 2020

順天堂大学医学部附属静岡病院＼cjkstart脳神経外科(受稿日 2018. 10. 15)(脱稿日 2018. 11. 19)〔連絡先：テ 410-2295 静岡県伊豆の国市長岡 1129 順天堂大学医学部附属静岡病院 脳神経外科 山本拓史] [Address correspondence: Takuji YAMAmoto, M.D., Department of Neurosurgery, Juntendo University Shizuoka Hospital, 1129 Nagaoka, Izunokuni, Shizuoka 410-2295, Japan] 


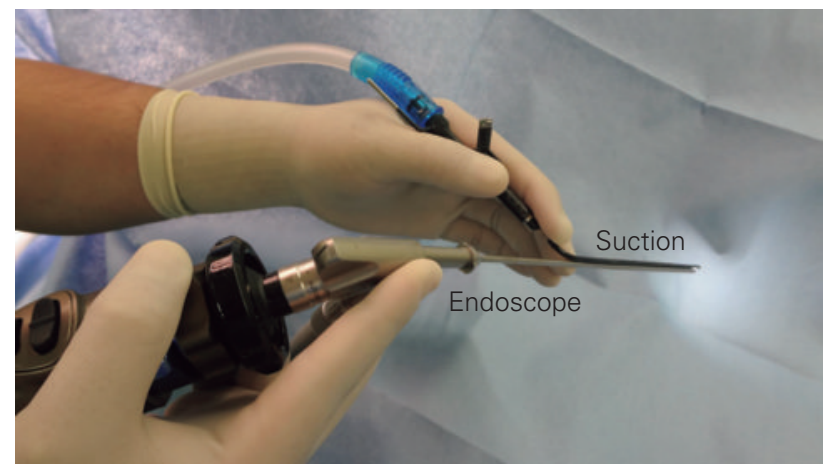

Fig. 1 Endoscope and suction tube.

Special equipment is required for endoscopic hematoma evacuation. The ridged endoscope is designed to be held in the right hand and the suction tube in the left.

用も可能であり，その意義は大きい，本稿では，筆者らの 経験をもとに内視鏡下血腫除去術における基本手技を詳述 するとともに，注意すべき問題点について述べる.

\section{内視鏡下血腫除去術の適応について}

内視鏡下血腫除去術を含む脳内出血に対する外科的治療 の適応は，脳卒中治療ガイドライン $2015^{11}$ に準ずる．ただ し, 内視鏡手術に関してエビデンスレベルの高い研究は少 なく, 内視鏡手術の推奨度は高くない. それゆえ, 低侵襲 手技の利点を生かした外科的治療を目指し, 個々の症例に て適応を検討すべきである.内視鏡手術の特性を生かすこ とで, ガイドラインでは推奨度の低い視床出血などの病態 に対しても血腫除去により病状の改善がみられる症例もあ り, 術者の技量も考慮のうえ, 手術適応を決定すべきであ $ろ^{7)}$.

\section{内視鏡下血腫除去術の手術機材について}

内視鏡下血腫除去術における標準手術では，硬性鏡を用 いる dry field method が一般的である ${ }^{25)-7)}$. その際, 準備 する機材には, 硬性鏡に加え血腫までのアプローチルート を確保する透明シース, 血腫吸引を行う吸引管が必要とな

\section{る(Fig. 1).}

透明シースは，硬性鏡，吸引管の太さによって制限を受 けることがあるため, 術前の確認が必要である. 汎用され る硬性鏡には外径 $2.7 \mathrm{~mm}$ と $4.0 \mathrm{~mm}$ があり, $2.7 \mathrm{~mm}$ 鏡と 比較して $4 \mathrm{~mm}$ 鏡のほうが視野角の広い映像が得られるも のの, 血腫除去術の場合より細径の内視鏡, 細径の透明 シースを選択し低侵襲性を優先するべきである(Fig. 2).

吸引管は内視鏡下血腫除去術用にデザインされたものを 選択し, シャフトの弯曲や折れ曲がりは, シース内操作の

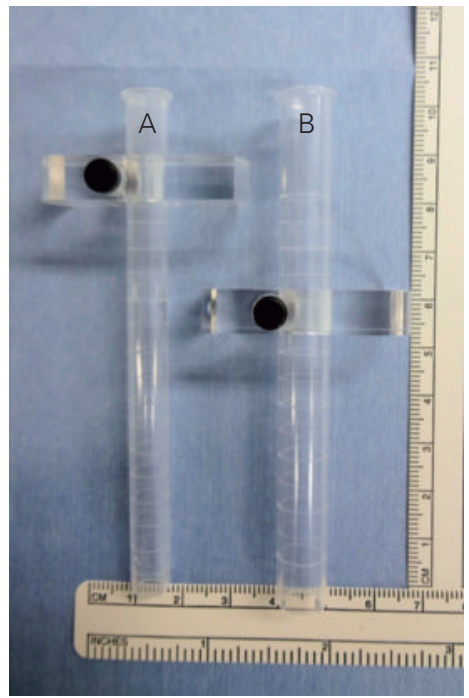

Fig. 2 Transparent sheath.

A: Outer diameter (OD) is $8 \mathrm{~mm}$, and the inner diameter (ID) is $6 \mathrm{~mm}$. $\mathbf{B}$ : The OD is $10 \mathrm{~mm}$, and the ID is $8 \mathrm{~mm}$. An appropriate sheath should be selected according to the endoscope.

妨げとなるため推奨されない，また，吸引管は血腫除去の みならず止血にも用いられる，そのため，止血機器(通常 はモノポーラー凝固装置)への接続端子, 接続コードが用 意された吸引管が使いやすい(Fig. 3).

\section{内視鏡下血腫除去術の基本手技}

内視鏡下血腫除去術の基本手技は, 穿頭, 穿刺, 吸引, 止血の 4 ステップからなる. 穿頭は, 血腫への trajectory の始点にもなり, 血腫摘出率や予後にも影響する場合があ り, おろそかにできない. 重要神経構造, 特に錘体路を破 壊しない trajectory を設定することが重要である．血腫形 状の長軸に沿った trajectoryはシースの可動範囲を軽減で きるが, 実際には長軸と無関係に穿刺しても摘出率に影響 を与えることは少なく, 神経路回避を優先すべきである. また，脳表の血管損傷にも注意すべきであり，術前造影検 査に扔いて評価が可能であれば，静脈損傷などを回避した 穿頭部位の設定が可能となる.

具体的には, 被殼出血, 脳室内血腫では, Kocher’s point 近傍に(Fig. 4), 小脳出血では出血側で乳様突起と後頭隆 起の中点に burr holeを穿つことが多い(Fig. 5). そし て, 皮質下出血では出血部位に応じて穿頭部位を変更する 必要がある ${ }^{6 / 7)}$.

穿頭では，いかなる部位の出血であっても十分な大きさ の burr hole を穿つこと重要である(Fig. 4). 多くの場合, 出血点は血腫と脳実質の境界に位置することが多く, 確実 な止血操作を行うためには十分にシースの可動性を確保す 

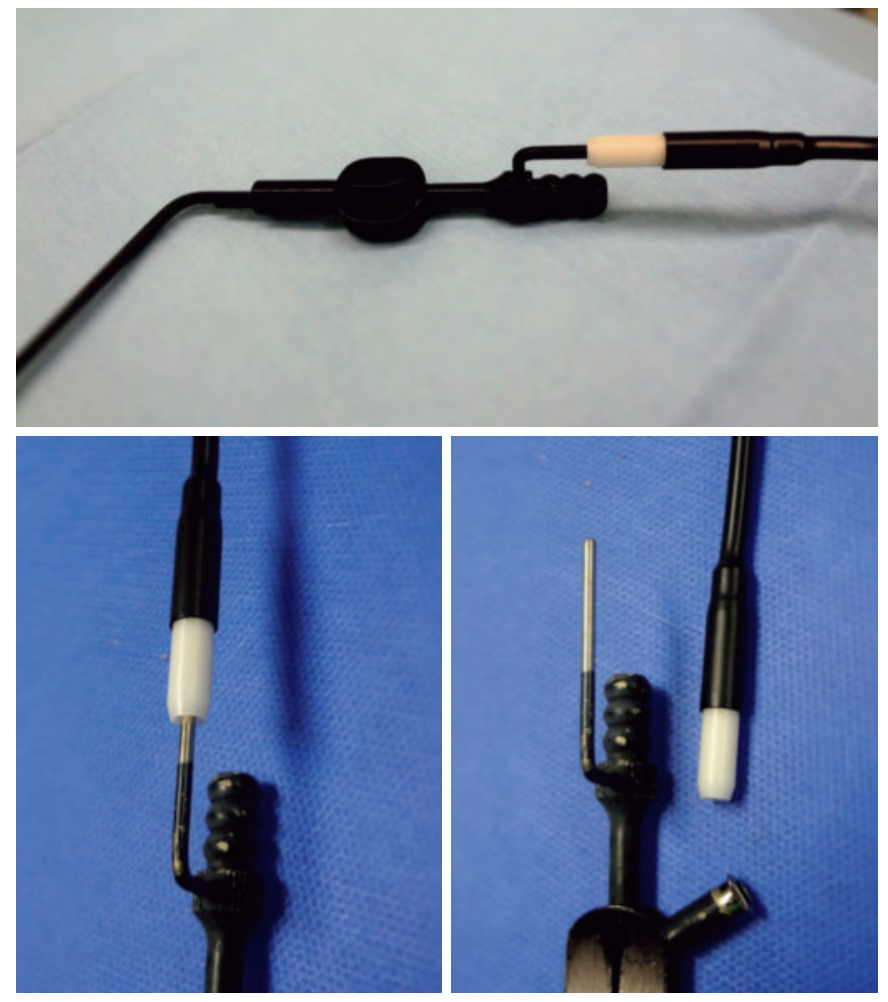

\section{$\frac{\text { A }}{\text { B }} \mathbf{C}$}

Fig. 3 Suction tube designed for endoscopic surgery.

This suction tube is designed to be connected to the energy device for hemostasis (A). The handling of the code is simple and is detachable (B, C).
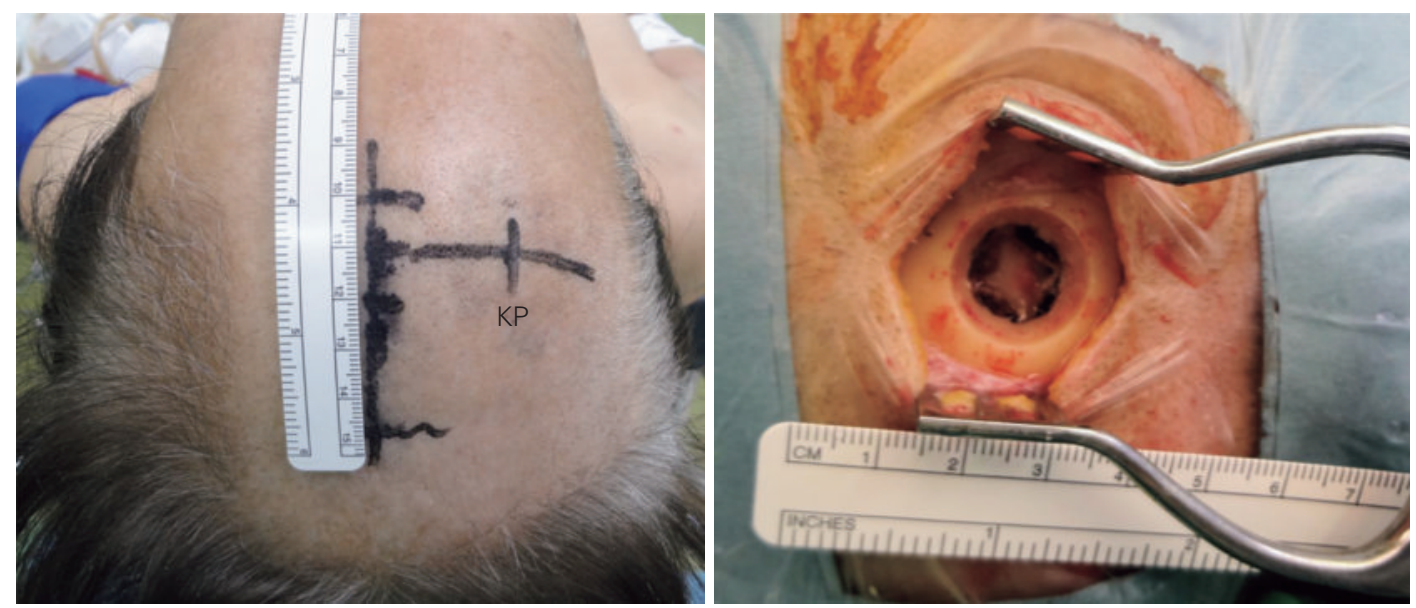

Fig. 4 Burr hole for putaminal hemorrhage and intraventricular hemorrhage. The burr hole should be made as large as possible near Kocher's point (KP).

る必要がある(Fig. 6)。術後の整容が問題となる場合には, burr hole buttonもしくはチタンプレートにて穿頭を閉鎖 する.

次いで血腫腔の穿刺を行うが，方向を誤ると重大な脳害 質損傷の原因となるため慎重に行うべきである，硬膜は骨 縁まで十分に切開するが，われわれは硬膜の再生も考慮 し，必要以上の焼灼は行わないようにしている。脳表血管 に注意しながら皮質切開 (corticotomy)を行うが, 切開が
不十分であると脳実質に挫滅をきたす可能性があるた め, 約 $10 \mathrm{~mm}$ の透明シースを挿入することを念頭に置 き, くも膜, 軟膜を広く切開する. 通常, 脳室穿刺針など の細径の穿刺針にて方向を確定したのち, 脳室ドレナージ チューブ (3 mm 径), 透明シース内筒 $(6 \mathrm{~mm}$ 径), 外筒 (6 mm 径) の順に穿刺し, 徐々に tractを拡張することで trajectory を完成する.

穿刺の際には, あらかじめ脳表から血腫胿までの距離を 


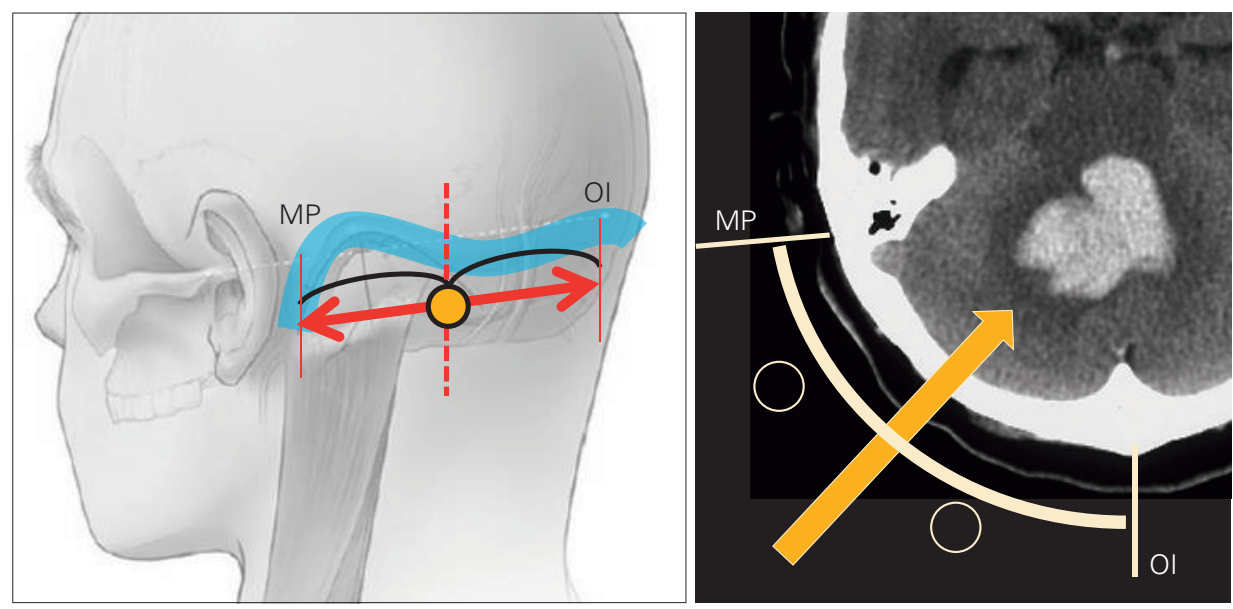

Fig. 5 Burr hole for cerebellar hemorrhage.

The burr hole should be made on the midpoint between the mastoid process (MP) and occipital inion (OI).
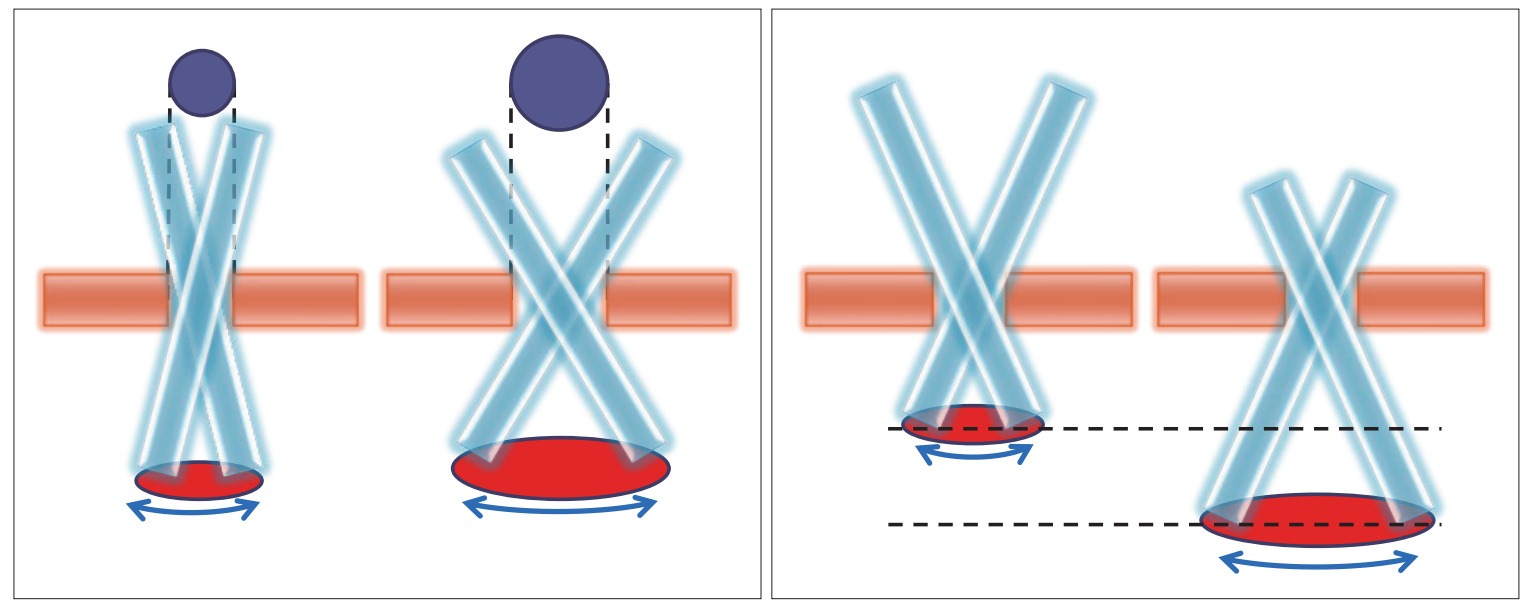

Fig. 6 Relationship between the burr hole size and the range of motion of the clear sheath.

A $\mid \mathbf{B}$ A: A larger range of motion is obtained with a larger burr hole. B: Deeper manipulation provides a greater range of motion than a shallow hematoma.

計測しておくとよい．筆者らは Kocher's point から被殼前 極，後極までの距離を navigation system を用いて計測し たところ，前極 $50.6 \mathrm{~mm}$, 後極 $60.2 \mathrm{~mm}$ であった (Table 1)。被殼出血では脳表から $50 \mathrm{~mm}$ で血腫に到達するはず であり，それ以上の深さに穿刺することは避けるべきであ る. 透明シース先端部は, 血腫の最浅部に留置できればよ く, シース内への血腫の逆流で確認可能である.

透明シースの血腫内への留置を確認し血腫吸引を開始す る。一般的には, 助手が透明シースを保持し術者が吸引 管，内視鏡を保持しながら手術を行う。下垂体手術のよう に内視鏡を固定することなく, 内視鏡を保持する術者が方 向を指示しながら手術を行うことで良好なオリエンテー ションを保ちながら血腫除去を進めることが可能となる.
血腫は浅いところから徐々に深部に向けて吸引すると明 るい視野が維持でき, 術野の視認性も良好となる，基本的 にシース先端を脳実質と血腫の境界部に留置, 軽くシース を動かすことで，透明シース直下に押し出された血腫を吸 引する，徐々に深部の血腫を吸引するが，吸引管のみを進 めるのではなく, シース, 内視鏡とともに媣部に進めると よい(Fig. 7).

血種吸引を進めると小血管からの出血に遭遇するが，止 血を後回しにせずその都度止血を行ったほうがよい．手術 操作が限られる内視鏡手術では，同時多発的な出血に陥る と dry field の確保が困難となり血腫吸引や止血に難渋す ることとなる.

止血操作は, 電気メスに接続した吸引管からの通電によ 
Table 1 Distance between Kocher's point and the putamen The distance between Kocher's point and the putamen was measured using a navigation planning system (Stealth Station, Medtronic Japan).

\begin{tabular}{lcc}
\hline Kocher's point to the & $\begin{array}{c}\text { Anterior pole of the putamen } \\
\text { (mean } \pm \text { SD) }\end{array}$ & $\begin{array}{c}\text { Posterior pole of the putamen } \\
\text { (mean } \pm \text { SD) }\end{array}$ \\
\hline Total $(\mathrm{mm}): \mathrm{n}=30$ & $50.6 \pm 4.63$ & $60.2 \pm 4.48$ \\
Female $(\mathrm{mm}): \mathrm{n}=15$ & $49.8 \pm 5.83$ & $60.7 \pm 5.78$ \\
Male $(\mathrm{mm}): \mathrm{n}=15$ & $51.1 \pm 3.37$ & $60.2 \pm 3.95$ \\
\hline
\end{tabular}

SD: standard deviation
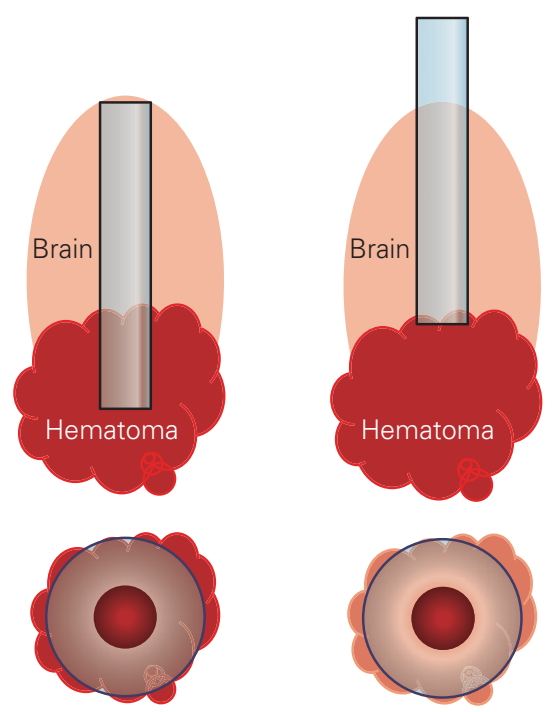

Fig. 7 Difference in brightness depending on the position of the sheath.

The tip of the sheath should be positioned on the boundary between the hematoma and the brain.

り燒灼凝固を行うが, その際, 低出力での焼灼が得られる 高周波メスが推奨される。通電時にいかに血液, 組織を炭 化させずに焼灼するかが大切で，組織が炭化すると吸引管 先端部に炭化組織が接着し，吸引管を外す際に炭化ととも に組織が剝がれ，再び出血を繰り返すこととなる。

確実な止血のためには，顕微鏡手術同様，正確に出血点 を同定することが重要で，血液を吸引し dry field を維持 しつつ焼灼する．出血点の同定が困難な場合は人工髄液を 用いた持続洗浄も有効で, 持続洗浄により止血効果も得ら れる. oozing 様の出血では, サージセルなどの止血材の 小片による圧迫も有効な止血手段となる．持続洗浄は止血 効果以外に血腫腔に新たな血腫を貯留させず流出させる目 的もあり, 持続洗浄の準備は怠らず用意すべきである.

十分な持続洗浄により残存血腫の有無と止血を確認 し, 内視鏡操作を終了する。止血が確認されれば, 必ずし もドレナージチューブは留置する必要はないが，脳室内血 腫では水頭症に備え留置することが多い。十分な血腫除
去, 減圧が完了した状態では, 脳実質が shrink し硬膜下 腔に大量の空気が混入することとなる，気脳症を予防する ために, 閉創直前に頭蓋内空気を減じる工夫を行うとよい.

\section{内視鏡下血腫除去術の視床出血脳室内穿破例への応用}

内視鏡手術を応用することで，従来手術適応に乏しかっ た脳内出血に対しても有効な外科的治療の可能性があ る. その 1 つが, 脳室内穿破をきたした視床出血である. 水頭症を併発した視床出血では, 一般的には脳室ドレナー ジ術の留置による髄液排出とそれに伴う受動的な血腫排出 が一般的であるが, Strahle らは脳室内の長期の血腫貯留 が脳室上衣細胞の機能障害を引き起こす可能性も示唆して 打り ${ }^{3)}$, 速やかな脳室内血腫除去が肝要と思われる. 海外 では血栓溶解剂を用いた臨床試験も実施されたが，十分な エビデンスを構築するにはいたっていない( ${ }^{8}$. 一方, 内視 鏡下血腫除去術では, 単純ドレナージや薬物療法以上に速 やかに機械的に血腫排除が可能で, 脳室穿破部位からの脳 内血腫摘出も可能であることより, 遷延性の血腫毒性 ${ }^{3)}$ 回避する可能性がある.

脳室内血腫には両側アプローチ法と片側アプローチ法が あるが，症例によっては片側アプローチで両側側脳室内の 血腫除去も可能となる, その場合, 透明中隔を経由し対側 側脳室へアプローチするが，透明中隔を開空する際には anterior septal vein の後方で通電した吸引管を用いると,

比較的安全な開空が可能となる ${ }^{5}$.

脳室内血腫の際，大きな視床出血では血腫による thalamic eminence の膨隆が側脳室後半部分へのアプローチ の妨げとなるが, 穿破部位より視床内血腫を摘出すること で mass effectを軽減, 後角へのアプローチが可能となる. 視床出血は thalamo-geniculate artery からの出血が多い が，その場合は血腫の最外側に出血点が位置するため, と きとして止血に難渋する場合があり注意を要する。した がって, 出血点をシースの延長上に想定し, あえて視床出 血の対側からのアプローチを行う場合もある. 視床出血で は, 出血の部位により出血源となる血管が異なるため, 出 血源に関する術前の評価も重要である 


\section{結 語}

内視鏡下血腫除去術を習得するためには，内視鏡関連機 材の特性を理解し，血腫吸引のための基本手技を習得する ことが必須である。そのためには，適切な指導者(日本神 経内視鏡学会技術認定医など)のもとでの指導が不可欠 で，ハンズオン講習会などを積極的に活用しつつ手技の習 得に努めるとよい．確実な手技のもとで行われる内視鏡手 術は，従来の開頭術と比較し明らかに低侵襲であるととも に，低侵襲でなくてはならない，新たな血腫除去への適応 も拡大されつつあるが，手技の習熟度に応じた術式を実施 することが重要である.

\section{文献}

1）日本脳卒中学会脳卒中ガイドライン委員会(編)：脳卒中治療 ガイドライン 2015. 協和企画, 東京, 2015, pp155-159

2) Nishihara T, Teraoka A, Morita A, et al: A transparent sheath for endoscopic surgery and its application in surgical evacuation of spontaneous intracerebral hematomas. J Neurosurg 92: 1053-1055, 2010

3) Strahle JM, Garton T, Bazzi AA, et al: Role of hemoglobin and iron in hydrocephalus after neonatal intraventricular hemorrhage. Neurosurgery 75: 696-705, 2014

4) Teramoto S, Yamamoto T, Nakao Y, et al: Novel anatomic classification of spontaneous thalamic hemorrhage classified by vascular territory of thalamus. World Neurosurg 104: 452458, 2017

5）山本拓史：神経内視鏡による脳室内血腫除去術. 伊達 勲 (編)：新 NS Now 13 脳室を征服するーアプローチとテク ニックの王道. メジカルビュー社, 東京, 2018, pp46-59

6) Yamamoto T, Nakao Y, Mori K, et al: Endoscopic hematoma evacuation for hypertensive cerebellar hemorrhage. Minim Invasive Neurosurg 49: 173-178, 2006

7）山本拓史, 中尾保秋, 徳川城治, ほか：被殼出血に対する神 経内視鏡の有効性. 脳卒中の外科 41: 183-186, 2013

8) Ziai WC, Tuhrim S, Lane K, et al: A multicenter, randomized, double-blinded, placebo-controlled phase III study of Clot Lysis Evaluation of Accelerated Resolution of Intraventricular Hemorrhage (CLEAR III ). Int J Stroke 9: 536-542, 2014 